\title{
Lusioersily
}

\section{Trajectories of change in internalizing symptoms during the COVID-19 pandemic: A longitudinal population-based study}

Hyland, P., Vallières, F., Daly, M., Butter, S., Bentall, R., Fox, R., Karatzias, T., MacLachlan, M., McBride, O., Murphy, J., Murphy, D., Spikol, E., \& Shevlin, M. (2021). Trajectories of change in internalizing symptoms during the COVID-19 pandemic: A longitudinal population-based study. Journal of Affective Disorders, 295, $1024-1031$. https://doi.org/10.1016/j.jad.2021.08.145

Link to publication record in Ulster University Research Portal

\section{Published in:}

Journal of Affective Disorders

Publication Status:

Published (in print/issue): 01/12/2021

DOI:

10.1016/j.jad.2021.08.145

\section{Document Version}

Publisher's PDF, also known as Version of record

\section{General rights}

Copyright for the publications made accessible via Ulster University's Research Portal is retained by the author(s) and / or other copyright owners and it is a condition of accessing these publications that users recognise and abide by the legal requirements associated with these rights.

\section{Take down policy}

The Research Portal is Ulster University's institutional repository that provides access to Ulster's research outputs. Every effort has been made to ensure that content in the Research Portal does not infringe any person's rights, or applicable UK laws. If you discover content in the Research Portal that you believe breaches copyright or violates any law, please contact pure-support@ulster.ac.uk. 
Research Paper

\title{
Trajectories of change in internalizing symptoms during the COVID-19 pandemic: A longitudinal population-based study
}

\author{
Philip Hyland ${ }^{\mathrm{a}, \mathrm{b}, *}$, Frédérique Vallières ${ }^{\mathrm{b}}$, Michael Daly ${ }^{\mathrm{a}}$, Sarah Butter ${ }^{\mathrm{c}}$, Richard P. Bentall ${ }^{\mathrm{c}}$, \\ Robert Fox ${ }^{\mathrm{d}}$, Thanos Karatzias ${ }^{\mathrm{e}, \mathrm{f}}$, Malcolm MacLachlan ${ }^{\mathrm{a}, \mathrm{g}}$, Orla McBride ${ }^{\mathrm{h}}$, Jamie Murphy ${ }^{\mathrm{h}}$, \\ David Murphy $^{\mathrm{b}}$, Eric Spikol ${ }^{\mathrm{a}}$, Mark Shevlin ${ }^{\mathrm{h}}$ \\ ${ }^{a}$ Department of Psychology, Maynooth University, Room 1.1.4 Education House, Kildare, Ireland \\ b Trinity Center for Global Health, Trinity College Dublin, Ireland \\ ${ }^{\mathrm{c}}$ Department of Psychology, The University of Sheffield, United Kingdom \\ ${ }^{\mathrm{d}}$ School of Nursing, Midwifery and Health Systems, University College Dublin, Ireland \\ ${ }^{\mathrm{e}}$ School of Health and Social Care, Edinburgh Napier University, United Kingdom \\ ${ }^{\mathrm{f}}$ Rivers Center for Traumatic Stress, NHS Lothian, United Kingdom \\ ${ }^{g}$ HSE National Clinical Programme for People with Disability, Ireland \\ ${ }^{\mathrm{h}}$ School of Psychology, Ulster University, United Kingdom
}

\section{A R T I C L E I N F O}

\section{Keywords:}

Covid-19

Mental health

Depression

Anxiety

Internalizing

Longitudinal

\begin{abstract}
A B S T R A C T
Background: Longitudinal data indicates that the mental health of the general population may not have been as badly affected by the COVID-19 pandemic as some had feared. Most studies examining change in mental health during the pandemic have assumed population homogeneity which may conceal evidence of worsening mental health for some. In this study, we applied a heterogeneous perspective to determine if there were distinct groups in the population characterised by different patterns of change in internalizing symptoms during the pandemic. Methods: Self-report data were collected from a nationally representative sample of Irish adults $(N=1041)$ at four time-points between April and December 2020.

Results: In the entire sample, mean levels of internalizing symptoms significantly declined from March to December 2020. However, we identified four distinct groups with different patterns of change. The most common response was 'Resilience' (66.7\%), followed by 'Improving' (17.9\%), 'Worsening' (11.3\%), and 'Sustained' (4.1\%). Belonging to the 'Worsening' class was associated with younger age, city dwelling, current and past treatment for a mental health problem, higher levels of empathy, and higher levels of loneliness.

Limitations: Sample attrition was relatively high and although this was managed using robust statistical methods, bias associated with non-responses cannot be entirely ruled out.

Conclusion: The majority of adults experienced no change, or an improvement in internalizing symptoms during the pandemic, and a relatively small proportion of adults experienced a worsening of internalizing symptoms. Limited public mental health resources should be targeted toward helping these at-risk individuals.
\end{abstract}

\section{Introduction}

Following the outbreak of COVID-19, fears were expressed that a rapid and perceptible rise in mental health problems might occur in the general population (Adhanom Ghebreyesus, 2020; Campion et al., 2020; Reger et al., 2020; Torjesen, 2020). Researchers around the world began to assess the prevalence of common mental health disorders such as depression, generalized anxiety, and posttraumatic stress in the general population. These findings have been summarised in several meta-analyses (Arora et al., 2020; Bueno-Notivol et al., 2021; Cénat et al., 2021; Cooke et al., 2020; Salari et al., 2020; Santabárbara et al., 2020; Wu et al., 2021). The pooled prevalence estimates of depression ranged from $16 \%$ (Cénat et al., 2021) to 34\% (Salari et al., 2020), with a mean of $26 \%$; generalized anxiety ranged from $15 \%$ (Cénat et al., 2021) to $32 \%$ (Salari et al., 2020; Wu et al., 2021), with a mean of $26 \%$; and posttraumatic stress ranged from $22 \%$ (Cénat et al., 2021) to $33 \%$ (Arora et al., 2020), also with a mean of $26 \%$. Although vital in revealing what proportion of the general population were potentially suffering

\footnotetext{
* Corresponding author at: Department of Psychology, Maynooth University, Room 1.1.4 Education House, Kildare, Ireland.

E-mail address: philip.hyland@mu.ie (P. Hyland).
} 
from common mental health disorders in the first months following the COVID-19 outbreak, these data revealed little about whether the prevalence of such disorders changed because of, or during, the pandemic.

Findings from a meta-analysis examining changes in various mental health problems from before and after the outbreak of COVID-19 found a small increase $(g=.17)$ in symptoms of anxiety and depression (Prati and Mancini, 2021). Longitudinal studies of the general populations of the United Kingdom and the United States that tracked changes in mental health from before the pandemic and through the first year found that early increases in anxiety and depression disappeared within several months (Daly and Robinson, 2021a, 2021b). Moreover, a longitudinal study from Brazil found no changes in depression from before and during the pandemic, and a significant decrease in anxiety (Brunoni et al., 2021). Thus, to date, disruption to population mental health caused by COVID-19 does not seem to have been as severe as was initially predicted.

These findings are consistent with what psychological science has known about human responses to stressful life events for several decades. It is well-established that only a small proportion of people who experience stressful life events will subsequently develop clinically significant levels of distress (Bonanno, 2004; Breslau et al., 1991; Bryant, 2019; Norris, 1992), and that there is considerable heterogeneity in mental health responses to life stressors (Bonanno, 2004; Galatzer-Levy et al., 2018). Reviews of such literature show that the modal response $(\sim 65 \%)$ to life stressors is resilience. That is to say that most people maintain good mental health irrespective of the severity of the stressful event. Moreover, $\sim 20 \%$ of people experience improvements in their mental health, $\sim 9 \%$ experience a decrease in their mental health, and $\sim 10 \%$ experience persistent mental health problems following stressful life events (Bonanno, 2004; Galatzer-Levy et al., 2018). Although debates exist as to whether or not the COVID-19 pandemic can be defined as a 'stressful' or 'traumatic' life event (Bridgland et al., 2021; Shevlin et al., 2020; Van Overmeire et al., 2020), the extant literature on human responses to challenging life events indicates that the majority of people in the general population should experience either no change or an improvement in their mental health during the pandemic, and only a small proportion of people should experience a decline in their mental health.

Although it is essential to know what proportion of the general population met criteria for common mental health disorders at the outset of the COVID-19 pandemic, and if these proportions changed during the pandemic, this approach is limited because it assumes two types of population homogeneity: homogeneity of initial response and homogeneity of change over time. Studies that have presented such estimates are inferring that they adequately describe the entire population despite the fact that there is known heterogeneity in initial response and change over time (Galatzer-Levy et al., 2018). Multiple studies have recently been published which address this issue. In a study of adults from the Rhine-Main region of Germany who were assessed during the first two months of lockdown, $84 \%$ experienced no change or an improvement in their mental health; $8 \%$ experienced an initial worsening before recovering, and $8 \%$ suffered a sustained worsening of their mental health (Ahrens et al., 2021). In a nationally representative sample of the general population of the United Kingdom who were tracked over the first four months of the pandemic, between $72 \%$ and $93 \%$ of people experienced no change or an improvement in their mental health (Shevlin et al., 2021). Factors associated with decreasing mental health during the pandemic were having a history of mental health problems, higher levels of loneliness, lower levels of resilience, lower levels of internal locus of control, higher levels of death anxiety, and higher levels of intolerance of uncertainty.

Recognizing heterogeneity in mental health at the population level is important because it has been shown to improve predictions about who will develop mental health problems (Galatzer-Levy and Bonanno, 2014), what the long-term health and mortality outcomes of these problems will be (Malgaroli et al., 2017), and how people will respond to treatment (Galatzer-Levy et al., 2013). It is likely, therefore, that taking a heterogeneous perspective on the mental health of the general population during the COVID-19 pandemic will improve our ability to accurately describe the mental health of the general population during this time, to identify those in the population who have experienced a decrease in their mental health, and to identify risk factors associated with deteriorating mental health problems. Ultimately, such discoveries should allow for more effective resource allocation and targeted clinical interventions.

In this study, we used data collected between April and December 2020 from a nationally representative sample of Irish adults to describe and explain different patterns of change in internalizing symptoms. The first objective was to determine if there was a significant change in internalizing symptoms for the entire sample across the study period. Based on existing longitudinal data (Ahrens et al., 2021; Daly and Robinson, 2021a, 2021b; Shevlin et al., 2021), we hypothesised that there would be either no change or a decline in internalizing symptoms between April and December 2020. The second objective was to determine if there was heterogeneity in internalizing symptoms at baseline, and in the change of these symptoms over time. Consistent with the general psychological literature (Bonanno, 2004; Galatzer-Levy et al., 2018), and emerging data from the COVID-19 pandemic (Ahrens et al., 2021; Shevlin et al., 2021), we hypothesised that there would be evidence of heterogeneous change over time, and that the majority of individuals would be characterised by experiencing no change or an improvement in their internalizing symptoms. We also expected to find a small portion of individuals who experienced worsening internalizing symptoms during the pandemic. The third objective was to identify psychosocial variables associated with different patterns of change in internalizing symptoms during the pandemic. Given the paucity of relevant evidence, this objective was approached in an exploratory manner.

\section{Methods}

\subsection{Participants and procedures}

This study is based on data collected from the Irish arm of the COVID19 Psychological Research Consortium (C19PRC) study; a longitudinal, internet-based survey designed to assess the population's psychological and social adjustments to the pandemic (McBride et al., 2020). All data were collected by the survey company Qualtrics, and participants were recruited from traditional, actively managed, double-opt-in research panels via email, SMS, or in-app notifications. Quota sampling methods were used to recruit a sample that was nationally representative in terms of sex, age, and geographical distribution, as Irish census data (Central Statistics Office of Ireland, 2020). Evidence of the nationally representative nature of the sample data can be found elsewhere (Spikol et al., 2021). Inclusion criteria were that respondents were aged 18 years or older, residing in the Republic of Ireland, and capable of completing the survey in English. Participants were remunerated by Qualtrics, and informed consent was obtained from all participants. Ethical approval was granted by the research ethics committees at Maynooth University, the University of Sheffield, and Ulster University.

Wave 1 (31st March-5th April 2020, $N=1041$ ) occurred during the first week of Ireland's initial lockdown period; Wave 2 (30th April-19th May 2020, $n=506$, recontact rate $=49 \%$ ) took place approximately six weeks later to coincide with the end of the nationwide lockdown; Wave 3 (16th July-8th August 2020, $n=534$, recontact rate $=51 \%$ ) occurred during the summer period when public health restrictions were low; and Wave 4 (2nd December-22nd December 2020, $n=416$, recontact rate $=40 \%$ ) occurred toward the end of 2020 , and again during a period of few public health restrictions. All participants from Wave 1 were recontacted at each subsequent wave and were requested to participate. In total, 327 people (31\%) participated at all four assessments. Sociodemographic characteristics of the sample at Wave 1 are presented in 
Table 1

Sociodemographic Characteristics and Descriptive Statistics at Wave $1(N=$ 1041).

\begin{tabular}{|c|c|c|}
\hline & $\%$ & Mean (SD), Range \\
\hline \multicolumn{3}{|l|}{ Sex } \\
\hline Female & 51.5 & \\
\hline Male & 48.2 & \\
\hline \multicolumn{3}{|l|}{ Age group (years) } \\
\hline $18-24$ & 11.1 & \\
\hline $25-34$ & 19.2 & \\
\hline $35-44$ & 20.6 & \\
\hline $45-54$ & 15.9 & \\
\hline $55-64$ & 21.0 & \\
\hline $65+$ & 12.2 & \\
\hline \multicolumn{3}{|l|}{ Birthplace } \\
\hline Ireland & 70.7 & \\
\hline \multicolumn{3}{|l|}{ Region of Ireland } \\
\hline Leinster & 55.3 & \\
\hline Munster & 27.3 & \\
\hline Connaught & 12.0 & \\
\hline Ulster & 5.4 & \\
\hline \multicolumn{3}{|l|}{ Living location } \\
\hline City & 24.5 & \\
\hline Suburb & 18.1 & \\
\hline Town & 26.8 & \\
\hline Rural & 28.8 & \\
\hline \multicolumn{3}{|l|}{ Highest Education } \\
\hline No qualification & 1.2 & \\
\hline Finished mandatory schooling & 6.4 & \\
\hline Finished secondary school & 22.4 & \\
\hline Undergraduate degree & 22.5 & \\
\hline Postgraduate degree & 19.8 & \\
\hline Other technical qualification & 27.9 & \\
\hline \multicolumn{3}{|l|}{2019 income } \\
\hline $0-€ 19,999$ & 24.6 & \\
\hline$€ 20,000-€ 29,999$ & 21.3 & \\
\hline$€ 30,000-€ 39,999$ & 19.5 & \\
\hline$€ 40,000-€ 49,999$ & 12.7 & \\
\hline$€ 50,000+$ & 21.9 & \\
\hline \multicolumn{3}{|l|}{ Employment status } \\
\hline Full-time (self)/employed & 43.3 & \\
\hline Part-time (self)/employed & 15.7 & \\
\hline Retired & 15.0 & \\
\hline Unemployed & 8.4 & \\
\hline Student & 6.3 & \\
\hline Unemployed (disability or illness) & 5.6 & \\
\hline Unemployed due to COVID-19 & 5.7 & \\
\hline \multicolumn{3}{|l|}{ Employed face-to-face with public } \\
\hline Yes & 40.7 & \\
\hline \multicolumn{3}{|l|}{ Religion } \\
\hline Christian & 69.8 & \\
\hline Muslim & 1.6 & \\
\hline Jewish & 0.2 & \\
\hline Hindu & 1.1 & \\
\hline Buddhist & 0.6 & \\
\hline Sikh & 0.1 & \\
\hline Other religion & 3.8 & \\
\hline Atheist & 15.3 & \\
\hline Agnostic & 7.5 & \\
\hline \multicolumn{3}{|l|}{ Living alone } \\
\hline Yes & 18.4 & \\
\hline \multicolumn{3}{|l|}{ Children in the household } \\
\hline Yes & 39.7 & \\
\hline \multicolumn{3}{|l|}{ Diagnosed with a chronic illness } \\
\hline Yes & 16.7 & \\
\hline Treatment for a mental health problem & & \\
\hline Currently receiving treatment & 9.4 & \\
\hline Received treatment in the past & 19.3 & \\
\hline Perceived risk of COVID-19 infection & & 44.63 (26.07), $0-100$ \\
\hline Empathy & & 33.49 (6.85), 9-45 \\
\hline Intolerance of uncertainty & & 40.28 (14.98), $12-84$ \\
\hline Internal locus of control & & 8.94 (3.16), 3-21 \\
\hline Loneliness & & 4.97 (1.87), 3-9 \\
\hline
\end{tabular}

Table 1. Respondents at each follow-up significantly differed $(\mathrm{ps}<.05)$ from non-responders on a range of sociodemographic variables including being older, being more likely to have been born in Ireland, to not be living in a city, to be retired, to have a pre-existing health condition, and to have had a confirmed or suspected COVID-19 infection. Management of missing data is explained in the data analysis section.

\subsection{Measures}

Depression: Symptoms of major depression were measured using the nine-item Patient Health Questionnaire-9 (PHQ-9) (Kroenke et al., 2001). Participants indicate how often they have been bothered by each symptom over the last two weeks on a four-point Likert scale that ranges from 0 (Not at all) to 3 (Nearly every day). Scores range from 0 to 27 with higher scores reflecting greater symptomatology. The psychometric properties of the PHQ-9 scores have been evidenced (Manea et al., 2012), and the internal reliability (Cronbach's alpha) of the scale scores in this sample at each wave were greater than .90 .

Anxiety: Symptoms of generalized anxiety were measured using the Generalized Anxiety Disorder 7-item Scale (GAD-7) (Spitzer et al., 2006). Participants indicate how often they have been bothered by each symptom over the last two weeks on a four-point Likert scale that ranges from 0 (Not at all) to 3 (Nearly every day). Scores range from 0 to 21 with higher scores reflecting greater symptomatology. The GAD-7 scale scores have been shown to produce reliable and valid scores in community studies (Hinz et al., 2017), and the internal reliability of the scale scores in the current sample at each wave were greater than 90 .

Posttraumatic stress: Symptoms of posttraumatic stress were measured using the six-item PTSD module of the International Trauma Questionnaire (ITQ: Cloitre et al., 2018). Participants were instructed to indicate how bothered they have been over the last month in relation to their experiences of the COVID-19 pandemic. The ITQ uses a five-point Likert scale that ranges from 0 (Not at all) to 4 (Extremely). Total symptom scores range from 0 to 24 with higher scores indicating higher levels of posttraumatic stress symptomatology. The ITQ has been shown to produce reliable and valid scale scores in multiple samples (Cloitre et al., 2018; Vallières et al., 2018), and the internal reliability of the scale scores in this sample at each wave were all greater than .90 .

These three measures were used to create an 'internalizing' symptom score for analytic purposes. Scores of the three scales were significantly (ps $<.001$ ) correlated at Waves 1 (mean $r=.65$ ), 2 (mean $r=.71$ ), 3 (mean $r=.73$ ), and 4 (mean $r=.78$ ). The internal reliability estimate of the 22 items at Wave 1 was $\alpha=.95$. A composite variable for internalizing symptoms was created at each wave by averaging the total score of the three scales $(0-72 / 3)$. This created a variable with possible scores ranging from 0 to 24 where higher scores reflect higher levels of internalizing symptoms.

\section{Predictor variables}

Several predictor variables were selected from Wave 1 including age, sex, city dwelling, number of children in the home, living alone, 2019 income, diagnosis of a chronic physical health problem prior to the COVID-19 outbreak, current and past treatment for a mental health problem, and perceived risk of contracting COVID-19 in the next month (measured using a slider scale ranging from 0 ['No risk'] to 100 ['Great risk']).

Empathy was measured using the nine-item Identification with all Humanity Scale (McFarland et al., 2012). Participants responded to three statements with reference to three groups: 'people in my community', 'people from Ireland', and 'all humans everywhere'. The response scale ranged from 'not at all' (1) to 'very much' (5) with higher scores reflecting higher levels of empathy. Internal reliability was excellent $(\alpha=.92)$.

Intolerance of uncertainty was measured using the 12-item Intolerance of Uncertainty Scale (Buhr and Dugas, 2002) which is answered 
using a five-point Likert scale ranging from 'not at all characteristics of me' (1) to 'entirely characteristic of me' (5). Higher scores reflect higher levels of intolerance of uncertainty, and internal reliability was good ( $\alpha$ $=.87$ ).

Internal locus of control was measured using the three-item subscale of the Locus of Control Scale (Sapp and Harrod, 1993). Statements are answered on a seven-point Likert scale ranging from 'strongly disagree' (1) to 'strongly agree' (7), and higher scores reflect higher levels of internal locus of control. Internal reliability was acceptable $(\alpha=.67)$.

Loneliness was measured using the three-item Loneliness Scale (Hughes et al., 2004), which was designed for population-based surveys. Respondents indicate how often they feel that they lack companionship, feel left out, and feel isolated from others. Responses are based on a three-point scale including 'hardly ever' (1), 'sometimes' (2), and 'often' (3). Higher scores reflect higher levels of loneliness, and internal reliability was good $(\alpha=.87)$.

\subsection{Data analysis}

The research objectives were addressed in three analytic phases, and all analyses were performed using Mplus 8.2 (Muthén and Muthén, 2018). First, mean levels of internalizing symptoms were compared across the four waves using structural equation modeling so that missing data were handled via full-information robust maximum likelihood estimation (MLR: Schafer and Graham, 2002). This approach is recognised as the optimal method for handling missing data (Schafer and Graham, 2002) as it uses all available information to estimate missingness at future waves ensuring no loss of statistical power or sample representativeness, and can handle non-normally distributed continuous variables (Enders and Bandalos, 2001). A 'null' model was initially estimated where the internalizing means were constrained to be equal across time, followed by an 'alternative' model where the means were freely estimated. These models differ by three degrees of freedom and improvement in model fit is assessed using a loglikelihood difference test which follows a chi-square $\left(\chi^{2}\right)$ distribution. Pairwise comparisons were performed using a Wald $\chi^{2}$ test.

Second, latent variable mixture modeling was used to determine if there were different trajectories of change in internalizing symptoms (Muthén and Muthén, 2000; Muthén and Shedden, 1999). The baseline model was a latent growth model (LGM) with four observed variables representing internalizing symptoms at Waves 1-4. The loadings on the intercept latent variable were fixed at 1 so that the mean of the latent variable represented the average internalizing score at Wave 1 . If the variance of the intercept latent variable was statistically significant, the null hypothesis that all participants had the same level of internalizing symptoms at Wave 1 was rejected. The loadings for the slope latent variable were fixed at $0,1,2$, and 3 to represent linear change over time. A linear model provided superior fit to the data than a quadratic model. The mean of this latent variable represents the rate of change in internalizing symptoms over time. If the variance of the slope latent variable was statistically significant, this indicated that that there was variability in participants' rate of change over time.

Significant variability in the intercept and the slope indicates heterogeneity in the initial status and rate of change of internalizing symptoms. In this case, the heterogeneity can be modeled by adding a mixture component to the model to test if there were homogenous classes that shared similar within-class levels of initial status and rate of change. To accomplish this, latent classes were added successively to the LGM, with one to six class models being estimated. Growth mixture models (GMMs: Muthén, 2001) were used to model the longitudinal trajectories. GMM is a flexible form of LGM that tests for multiple homogeneous classes with different intercepts and slopes. Different between-class intercept and slopes were estimated as the mean (and variance) of the class-specific intercept and slope latent variables. GMM permits within-class variation for the intercept and slope latent variables, and the slope-intercept correlation was also estimated (although invariant across classes). The parameters of the LGM and GMMs were estimated using the MLR estimator.

To avoid solutions based on local maxima, 200 random sets of starting values were used followed by 50 final stage optimizations. The fit of the baseline LGM was assessed using standard criteria: acceptable fit was indicated by non-significant $\chi^{2}$, Tucker-Lewis Index (TLI) and Comparative Fit Index (CFI) values $\geq .90$, Root Mean Square Error of Approximation (RMSEA) and Standardized Root Mean Square Residual $($ SRMR) $\leq .08$. The relative fit of the GMM models was compared using three information theory based fit statistics: the Akaike Information Criterion (AIC: Akaike, 1987), the Bayesian Information Criterion (BIC: Schwarz, 1978) and the sample size adjusted Bayesian Information Criterion (ssaBIC: Sclove, 1987). The solution with the lowest value is superior, or if no minimum is found then the 'diminishing gains in model fit' (Masyn, 2013) for additional classes can be examined. Simulation studies suggest that the BIC is the best information criterion for identifying the correct number of classes (Nylund et al., 2007). Additionally, the Lo-Mendell-Rubin adjusted likelihood ratio test (LMR-A: Lo et al., 2001) was used to compare models with increasing numbers of latent classes. When a non-significant value occurs, the model with one fewer class should be accepted. Model convergence, replication of the log-likelihood, entropy values, the plausibility of the model estimates, and the interpretability of the model solutions were also used to judge the adequacy of each model.

Finally, predictor variables were added to the optimal GMM solution to determine which variables were associated with membership of each latent class. A 3-step approach was used so that the inclusion of the predictor variables did not influence the formation of the classes (Asparouhov and Muthén, 2014; Kim et al., 2016). All predictor variables were associated with the class intercept rather than the class slope.

\section{Results}

\subsection{Objective 1: change in internalizing symptoms}

Means and standard deviations of internalizing symptoms at each wave are presented in Table 2 . The model with freely estimated means was a significantly better fit to the data than the model with equal means $\left(\chi^{2}(3, N=1041)=9.25, p=.026\right)$, indicating that internalizing symptoms changed over time. Pairwise comparisons showed that internalizing symptoms were significantly lower at Wave 4 compared to Waves $1-3$, and these effects were all of a small magnitude.

Table 2

Overall and Pairwise Comparisons of Internalizing Symptoms from Waves 1 to 4 $(N=1041)$.

\begin{tabular}{lll}
\hline Internalizing symptoms & Mean & Standard deviation \\
Wave 1 & 5.30 & 5.04 \\
Wave 2 & 5.46 & 5.13 \\
Wave 3 & 5.43 & 5.24 \\
Wave 4 & 4.88 & 5.29 \\
Overall test of equality of means & $\chi^{2}=9.25, \mathrm{df}=3, p=.026$ \\
Pairwise comparisons & & \\
Wave 1 vs Wave 2 & $\chi^{2}=1.19, \mathrm{df}=1, p=.275, \mathrm{~d}_{\mathrm{rm}}=.05$ \\
Wave 1 vs Wave 3 & $\chi^{2}=0.61, \mathrm{df}=1, p=.434, \mathrm{~d}_{\mathrm{rm}}=.03$ \\
Wave 1 vs Wave 4 & $\chi^{2}=4.17, \mathrm{df}=1, p=.041, \mathrm{~d}_{\mathrm{rm}}=.09$ \\
Wave 2 vs Wave 3 & $\chi^{2}=0.04, \mathrm{df}=1, p=.835, \mathrm{~d}_{\mathrm{rm}}=.01$ \\
Wave 2 vs Wave 4 & $\chi^{2}=7.83, \mathrm{df}=1, p=.005, \mathrm{~d}_{\mathrm{rm}}=.15$ \\
Wave 3 vs Wave 4 & $\chi^{2}=7.70, \mathrm{df}=1, p=.006, \mathrm{~d}_{\mathrm{rm}}=.15$ \\
\hline
\end{tabular}

Note: $\chi^{2}=$ chi-square test; $\mathrm{df}=$ degrees of freedom; $\mathrm{p}=$ statistically significance; $\mathrm{d}_{\mathrm{rm}}=$ Cohen's $\mathrm{d}$ with a repeated measures correction; significant pairwise comparisons in bold. Wave $1=31$ st March -5 th April 2020; Wave $2=30$ th April - 19th May 2020; Wave $3=16$ th July -8 th August 2020; Wave $4=2$ nd December - 22nd December 2020. 


\subsection{Objective 2: heterogeneity in internalizing symptoms}

The baseline LGM was a well-fitting model $\left(\chi^{2}(5, N=1041)=8.52\right.$, $p=.129 ; \mathrm{CFI}=.99 ; \mathrm{TLI}=.99 ; \mathrm{RMSEA}=.03$ (90\% CI $=.00, .06)$; SRMR $=.02)$. The mean of the intercept latent variable was 5.35 ( $\mathrm{SE}=0.16, p$ $<.001$ ), and the mean of the slope was -0.08 (SE $=0.07, p=.266)$. The variance of the latent variables for the intercept $\left(\sigma^{2}=20.52, \mathrm{SE}=1.34\right.$, $p<.001)$ and slope $\left(\sigma^{2}=0.75, \mathrm{SE}=0.28, p<.01\right)$ were significant, indicating that there was variability in the initial levels and rate of change in internalizing symptoms that could be explored using GMM. The fit indices for the models with one to six classes are presented in Table 3.

All models terminated normally, and the log-likelihood values were replicated. The two- and four-class solutions were the only ones to have all parameters within acceptable boundaries, and the other models all had a non-positive definite within-class variance-covariance matrix. All information theory statistics decreased from one through to six classes, and the entropy was similar for all models. However, the decline in BIC values slowed considerably after four classes, suggesting that the fourclass solution may be optimal. The LMR-A test first became nonsignificant for the four-class model suggesting the superiority of the three-class model. However, the classes in this model differed only quantitatively in terms of the intercepts (low, medium, and high intercepts) with flat slopes, whereas the four-class model separated the 'medium' class into two qualitatively different classes suggesting that meaningful classes had been identified rather than just representing cutpoints on an underlying continuum. The entropy value for the four-class model (.81) indicated good delineation between classes (Celeux and Soromenho, 1996), and these classes were easily interpretable based on the profile plot. As such, the four-class model was deemed to be the best fit of the data and parameter estimates for this model are presented in Table 4.

Trajectories of change in internalizing symptoms over time are shown in Fig. 1 and the class sizes were based on most likely class membership based on a participant's posterior probabilities. Class 2 ('Resilient': 66.7\%) was the largest, and was characterised by a low internalizing mean at Wave 1 that remained stable over time, as evidenced by the non-significant slope. Class 1 ('Sustained': 4.1\%) was the smallest, and was characterised by a high internalizing mean at Wave 1 that remained stable over time, as indicated by the non-significant slope. The slopes for Classes 3 and 4 were significant indicating that both were defined by change over time. Class 3 ('Improving': $17.9 \%$ ) was characterised decreasing Internalizing means over time, while Class 4 ('Worsening': 11.3\%) was characterised by increasing Internalizing means over time. For all classes, the slope-intercept covariation was not statistically significant $\left(\operatorname{Cov}_{\mathrm{I}-\mathrm{S}}=-0.16, \mathrm{SE}=0.32, p=.621\right)$.

Table 3

Fit indices for latent class models of internalizing symptoms with 1-6 latent classes $(N=1041)$.

\begin{tabular}{lllllll}
\hline$N$ & $\begin{array}{l}\text { Log } \\
\text { likelihood }\end{array}$ & AIC & BIC & ssaBIC & $\begin{array}{l}\text { LMR-A } \\
(p-\end{array}$ & Entropy \\
1 & -6949.18 & 13924.36 & 13972.99 & 13947.39 & $\begin{array}{l}\text { value }) \\
-\end{array}$ & - \\
2 & -6831.05 & 13686.10 & 13745.47 & 13707.36 & $\begin{array}{l}236.99 \\
(<.001)\end{array}$ & 0.84 \\
3 & -6765.93 & 13561.85 & 13636.07 & 13588.43 & $\begin{array}{l}124.28 \\
(.003)\end{array}$ & 0.86 \\
4 & -6711.64 & 13459.27 & 13548.33 & 13491.16 & $\begin{array}{l}103.61 \\
(.220)\end{array}$ & 0.81 \\
5 & -6671.19 & 13384.37 & 13488.28 & 13421.58 & $\begin{array}{l}77.19 \\
(.331)\end{array}$ & 0.81 \\
& -6645.04 & 13338.07 & 13456.83 & 13380.60 & 49.91 & 0.82 \\
& & & & & $(.017)$ &
\end{tabular}

Note: $\mathrm{N}=$ number of classes; $\mathrm{AIC}=$ Akaike Information Criterion; $\mathrm{BIC}=$ Bayesian Information Criterion; ssaBIC = sample size adjusted Bayesian Information Criterion; LMR-A = Lo-Mendell-Rubin adjusted likelihood ratio test.

\subsection{Objective 3: correlates of class membership}

The correlates of class membership were identified using a multinomial logistic regression analysis, and the 'Resilient' class was the reference class for comparisons (Table 5).

Membership of the 'Sustained' class was significantly associated with younger age, having a chronic physical health problem, higher levels of intolerance of uncertainty, higher levels of loneliness, and strongly associated with current treatment for a mental health problem. Membership of the 'Worsening' class was significantly associated with younger age, city dwelling, current and past treatment for a mental health problem, higher levels of empathy, and higher levels of loneliness. Finally, membership of the 'Improving' class was significantly associated with younger age, having a chronic physical health problem, current and past treatment for a mental health problem, higher perceived risk of infection of COVID-19 in the next month, higher levels of empathy, higher levels of intolerance of uncertainty, higher levels of internal locus of control, and higher levels of loneliness.

\section{Discussion}

Despite fears expressed at the outset of the COVID-19 pandemic that there would be an increase in mental health disorders in the general population, the evidence to date suggests that there has, on average, been either no change or a decline in the prevalence of common mental health disorders in the general population during the pandemic. However, this overall trend may hide the fact that a small proportion of people in the population have experienced a deterioration of their mental health during the pandemic. This primary purpose of this study was to determine if there were distinct patterns of change in internalizing symptoms in the Irish adult population during the first nine months of the COVID-19 pandemic.

We first modeled change in internalizing symptoms in the sample as a whole - as is typical in the COVID-19 mental health research literature - and we found that there was a small decrease in internalizing symptoms between March and December 2020. Existing longitudinal evidence suggests that there was probably a small increase in symptoms of anxiety and depression at the very outset of the pandemic (Prati and Mancini, 2021), followed by a return to pre-pandemic levels within several months (Daly and Robinson, 2021a, 2021b). While we cannot know if levels of internalizing symptoms at our first assessment were higher than in the pre-pandemic period (due to study design), the small decline in symptoms observed in the current sample is consistent with several other population, longitudinal studies showing declines in symptoms of anxiety/depression/posttraumatic stress during the first year of the pandemic (Brunoni et al., 2021; Daly and Robinson, 2021a, 2021b; Shevlin et al., 2021).

Next, we modeled the sample data to determine if there was evidence of heterogeneity in initial internalizing symptoms and change over time. Consistent with the general psychological literature (Bonanno, 2004; Galatzer-Levy et al., 2018), and with data collected during the pandemic (Ahrens et al., 2021; Shevlin et al., 2021), we found evidence of both types of heterogeneity. Of most relevance, we found that patterns of change over time were best described by four profiles. The largest group of people, approximately two-thirds of the sample, were characterised by having consistently low symptoms of internalizing symptoms across the nine-month study period, while a very small proportion (4\%) were characterised by having sustained high levels of internalizing symptoms. Nearly one-in-five people (18\%) were characterised by experiencing a decline in internalizing symptoms, while only about one-in-ten were characterised by experiencing increasing symptoms. Consequently, our findings show that $89 \%$ of Irish adults experienced no change, or an improvement, in their mental health during the COVID-19 pandemic. These results are consistent with those reported from the Rhine-Main region of Germany during the first two months of the pandemic (Aherns et al., 2021), and from the United Kingdom during the first four 
Table 4

Class-specific parameter estimates for the 4-class models of internalizing symptoms.

\begin{tabular}{|c|c|c|c|c|c|c|c|c|}
\hline & \multicolumn{8}{|c|}{ Internalizing Symptoms } \\
\hline & Sustained & & Resilient & & Improving & & Worsening & \\
\hline & Mean (se) & Variance (se) & Mean (se) & Variance (se) & Mean (se) & Variance (se) & Mean (se) & Variance (se) \\
\hline Intercept & $17.05(0.73)^{* * *}$ & $2.57(0.66)^{* * *}$ & $2.412(0.13)^{* * *}$ & $2.57(0.66)^{* * *}$ & $11.64(0.86)^{* * *}$ & $2.57(0.66)^{* * *}$ & $7.41(0.90)^{* * *}$ & $2.57(0.66)^{* * *}$ \\
\hline Slope & $\begin{array}{l}0.01 \\
(0.29)\end{array}$ & $\begin{array}{l}0.14 \\
(0.19)\end{array}$ & $\begin{array}{l}-0.09 \\
(0.05)\end{array}$ & $\begin{array}{l}0.14 \\
(0.19)\end{array}$ & $\begin{array}{l}-1.74 \\
(0.53)^{* *}\end{array}$ & $\begin{array}{l}0.14 \\
(0.19)\end{array}$ & $\begin{array}{l}2.04 \\
(0.74)^{* *}\end{array}$ & $\begin{array}{l}0.14 \\
(0.19)\end{array}$ \\
\hline N (\%) & $42(4.1 \%)$ & & $698(66.7 \%)$ & & $187(17.9 \%)$ & & $115(11.3 \%)$ & \\
\hline
\end{tabular}

Note: $\mathrm{SE}=$ Standard Error; ${ }^{*} p<.05,{ }^{* *} p<.01,{ }^{* * *} p<.001$.

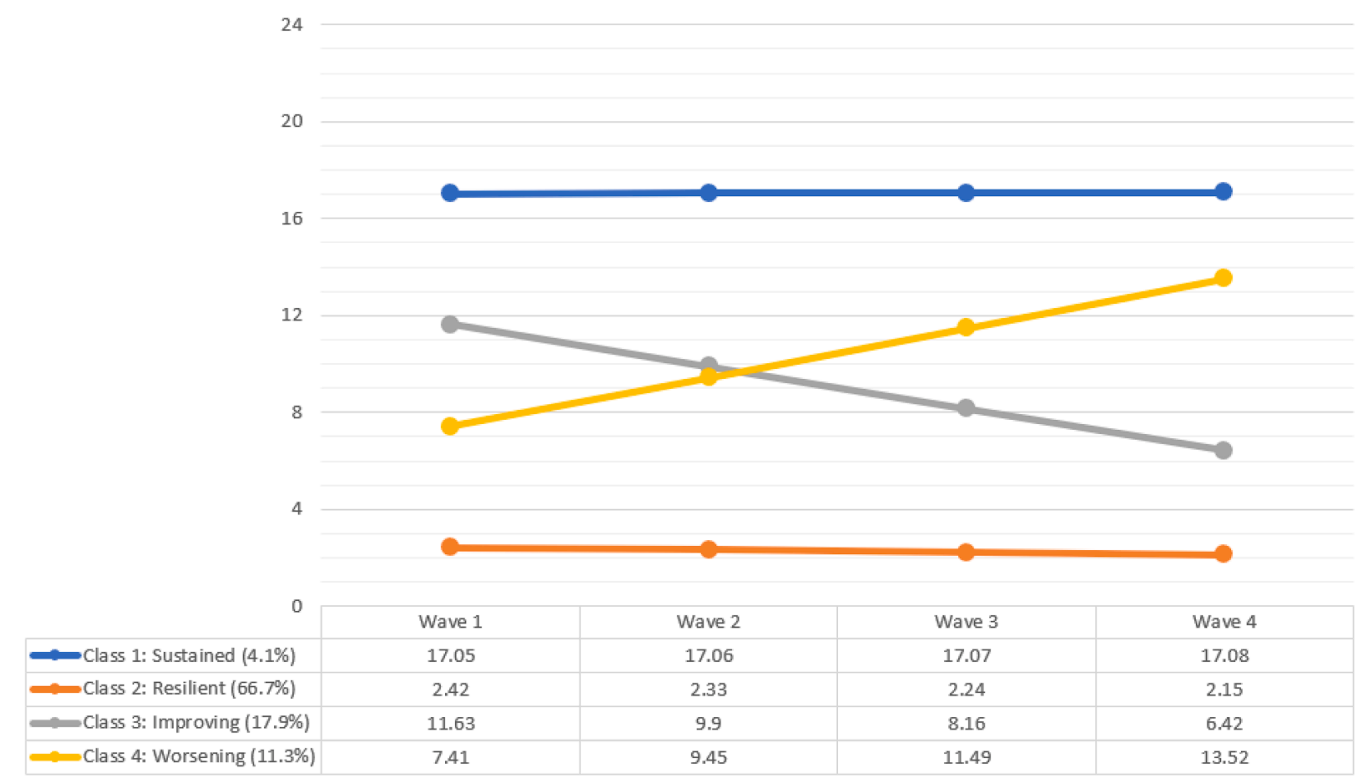

Fig. 1. Growth mixture model trajectories of internalizing symptoms.

Table 5

Odds Ratios (95\% confidence intervals) for Predictors of Internalizing Class Trajectories $(N=1041)$.

\begin{tabular}{llll}
\hline & Sustained & Improving & Worsening \\
& $(4.1 \%)$ & $(17.9 \%)$ & $(11.3 \%)$ \\
Age & $0.94^{*}$ & $0.96^{*}$ & $0.97^{*}$ \\
& $(0.90-0.99)$ & $(0.94-0.98)$ & $(0.94-0.99)$ \\
Gender (female) & 0.57 & 1.50 & 1.10 \\
City dwelling & $(0.12-2.80)$ & $(0.76-2.94)$ & $(0.52-2.31)$ \\
& 1.61 & 1.18 & $2.81^{*}$ \\
Children at home & $(0.36-7.17)$ & $(0.56-2.46)$ & $(1.26-6.27)$ \\
& 1.86 & 1.02 & 1.54 \\
Living alone & $(0.48-7.17)$ & $(0.54-1.93)$ & $(0.74-3.22)$ \\
& 0.04 & 0.93 & 1.51 \\
2019 Income & $(0.00-3.46)$ & $(0.35-2.49)$ & $(0.57-4.00)$ \\
& 1.02 & 1.20 & 1.07 \\
Chronic health problem & $(0.59-1.77)$ & $(0.98-1.45)$ & $(0.84-1.36)$ \\
& $8.24^{*}$ & $4.02^{*}$ & 1.98 \\
Mental health treatment: Past & $(1.76-38.66)$ & $(1.78-9.06)$ & $(0.76-5.17)$ \\
& 3.62 & $3.61^{*}$ & $4.80^{*}$ \\
Mental health treatment: & $(0.85-15.48)$ & $(1.81-7.21)$ & $(2.23-10.31)$ \\
Present & $88.00^{*}$ & $8.03^{*}$ & $7.01^{*}$ \\
Perceived COVID-19 risk & $(14.64-528.89)$ & $(2.16-29.83)$ & $(1.35-36.25)$ \\
& 1.02 & $1.02^{*}$ & 1.00 \\
Empathy & $(0.99-1.04)$ & $(1.01-1.03)$ & $(0.99-1.02)$ \\
Intolerance of uncertainty & $(0.97$ & $1.06^{*}$ & $1.07^{*}$ \\
Internal locus of control & $(1.03-1.11)$ & $(1.03-1.08)$ & $(0.995-1.051)$ \\
Loneliness & 0.96 & $1.14^{*}$ & 1.08 \\
& $(0.79-1.16)$ & $(1.03-1.26)$ & $(0.96-1.23)$ \\
& $3.31^{*}$ & $2.07^{*}$ & $1.85^{*}$ \\
& $(2.22-4.95)$ & $(1.70-2.53)$ & $(1.51-2.27)$ \\
\hline
\end{tabular}

Note: ${ }^{*}=p<.05$. Reference class is 'Resilient' class. months of the pandemic (Shevlin et al., 2021). Collectively, these findings are important because they show that the normative mental health response in the general population to the pandemic is one of stability/improvement.

We also sought to identify psychosocial variables that were associated with having different patterns of change in internalizing symptoms. Compared to the Resilient class, belonging to the Sustained class was strongly associated with currently receiving treatment for a mental health problem. This suggests that the individuals in this class may have already been experiencing high levels of internalizing symptoms prior to the COVID-19 pandemic. Furthermore, membership of this class was associated with several other established risk factors for internalizing distress including younger age, having a chronic health problem, higher levels of intolerance of uncertainty, and higher levels of loneliness (Caspi et al., 2014; Kotov et al., 2017).

Membership of the Improving and Worsening classes, compared to the Resilient class, was associated with many of the same variables including younger age, past and current treatment for a mental health problem, higher levels of empathy, and higher levels of loneliness. These effects may appear strange at first glance, but readers should bear in mind that the Improving and Worsening classes had higher levels of internalizing symptoms compared to the Resilient class at the outset of the pandemic. Therefore, these variables effectively identify those who belonged to classes that were more distressed at the outset of the pandemic but appear to be non-specific in terms of predicting increasing or decreasing symptoms over time. Some other factor(s) must be modulating how these variables influenced change in symptoms over time, and future research will be required to identify these moderators. One possible moderator may be social support. Loneliness is a wellestablished correlate of internalizing distress (Lim et al., 2020) and, 
thus, it was not surprising that higher levels of loneliness were associated with belonging to the Improving and Worsening classes. However, it is possible that individuals who felt lonely at the outset of the pandemic and who also lacked social support fared badly during the pandemic, while those who felt lonely at the outset of the pandemic but who had high levels of social supported fared well during the pandemic. This is speculative but our findings do raise attention to potentially valuable lines of future inquiry.

Some unique correlates of belonging to the Improving and Worsening classes were identified. Membership of the Worsening class was associated with living in a city, and this effect may be due to the increased risk of COVID-19 infection that was associated with living in a higher population density environment. Alternatively, public health restrictions on the movement of people, social gatherings, and conduct of businesses arguably caused the most disruption to daily activities within cities, and thus may be responsible for the increase in internalizing symptoms. It is also important to consider the types of people drawn to high density regions including those with high levels of extraversion and openness to experience who are particularly likely to enjoy social interaction and engagement with the arts and alternative lifestyles, respectively (Jokela et al., 2015). Curtailing opportunities to pursue such interests and opportunities may particularly affect the welfare of these individuals.

Membership of the Improving class was associated with a higher perceived risk of COVID-19 infection and higher levels of internal locus of control. Internal locus of control is a well-established correlate of good mental health (Kesavayuth et al., 2020) and has been linked to favourable mental wellbeing profiles during the pandemic (Fernandez-Rio et al., 2021). It is possible that during a time when many aspects of life were determined by external forces, the psychological disposition to believe that things are under one's own control was beneficial in alleviating psychological distress. Health problems and higher perceived risk of infection at the outset of the pandemic were also associated with improvements in internalizing symptoms. It may be that those with pre-existing health problems and those who perceived themselves to be at higher risk at the outset of the pandemic took steps to prepare themselves for the progression of the pandemic, and may have adapted quickly to their changing circumstances, which in turn led to reduced internalizing symptoms.

\section{Limitations}

First, our sample was not a random probability sample, and it was not possible to determine the response rate at Wave 1, therefore, these findings may not generalise to the entire Irish population. Second, while we could reasonably represent internalizing symptoms, we did not measure other dimensions of psychopathology such as externalizing or thought disorder problems (Kotov et al., 2017). Thus, our findings simply relate to changes in one area of psychopathology. Third, our analytic approach allowed us to identify how the various predictor variables were associated with the starting point of each class, but not necessarily the slope of these classes. Further research will be necessary to better understand which variables are associated with specific points of change over time. Fourth, there was substantial attrition in the sample across waves and although this was managed using robust statistical methods, this bias cannot be entirely accounted for. Finally, these findings come from one, high-income Western European nation and therefore may not generalize to socially and culturally distinct nations.

\section{Conclusion}

Between March and December 2020, there was a small decline in symptoms of anxiety/depression/posttraumatic stress in the general adult population of Ireland. Furthermore, this study adds to a burgeoning literature that indicates that the vast majority of people in the general population have experienced either no change or an improvement in their mental health during the first year of the pandemic. Nonetheless, there is evidence that a small proportion of people have experienced a worsening of the mental health during the pandemic, and these people are more likely to be younger, living in a city, experiencing current or have past mental health problems, to have higher levels of empathy, and higher levels of loneliness. Identifying those in population with mental health problems during the COVID-19 pandemic is a priority health policy for the Irish state (Health Service Executive, 2020), and these findings should aid in these efforts.

\section{Role of funding}

This research was supported by funding from the Health Research Board and the Irish Research Council under the COVID-19 Pandemic Rapid Response Funding Call [COV19-2020-025]. The funders had no role in the study design, data collection and analysis, decision to publish or preparation of the manuscript.

\section{CRediT authorship contribution statement}

Philip Hyland: Conceptualization, Formal analysis, Funding acquisition, Methodology, Writing - original draft. Frédérique Vallières: Funding acquisition, Writing - original draft. Michael Daly: Writing original draft. Sarah Butter: Data curation, Project administration, Writing - original draft. Richard P. Bentall: Writing - original draft. Robert Fox: . Thanos Karatzias: . Malcolm MacLachlan: . Orla McBride: Writing - original draft. Jamie Murphy: Writing - original draft. David Murphy: Conceptualization, Formal analysis, Methodology, Writing - original draft. Eric Spikol: . Mark Shevlin: Conceptualization, Writing - original draft.

\section{Declaration of Competing Interest}

None.

\section{Acknowledgments}

None.

\section{References}

Adhanom Ghebreyesus, T., 2020. Addressing mental health needs: an integral part of COVID-19 response. World Psychiatry 19, 129-130 official journal of the World Psychiatric Association (WPA).

Ahrens, K.F., Neumann, R.J., Kollmann, B., Plichta, M.M., Lieb, K., Tüscher, O., Reif, A., 2021. Differential impact of COVID-related lockdown on mental health in Germany. World Psychiatry 20, 140-141 official journal of the World Psychiatric Association (WPA).

Akaike, H., 1987. Factor analysis and AIC. Psychometrika 52, 317-332.

Arora, T., Grey, I., Östlundh, L., Lam, K., Omar, O.M., Arnone, D., 2020. The prevalence of psychological consequences of COVID-19: A systematic review and meta-analysis of observational studies. J. Health Psychol. https://doi.org/10.1177/ $1359105320966639,1359105320966639$.

Asparouhov, T., Muthén, B., 2014. Auxiliary variables in mixture modeling: using the BCH method in Mplus to estimate a distal outcome model and an arbitrary secondary model., Mplus Web Notes, pp. 1-22.

Bonanno, G.A., 2004. Loss, trauma, and human resilience: have we underestimated the human capacity to thrive after extremely aversive events? Am. Psychol. 59, 20-28.

Breslau, N., Davis, G.C., Andreski, P., Peterson, E., 1991. Traumatic events and posttraumatic stress disorder in an urban population of young adults. Arch. Gen. Psychiatry 48, 216-222.

Bridgland, V., Moeck, E.K., Green, D.M., Swain, T.L., Nayda, D.M., Matson, L.A., Hutchison, N.P., Takarangi, M., 2021. Why the COVID-19 pandemic is a traumatic stressor. PLoS One 16, e0240146. https://doi.org/10.1371/journal.pone.0240146.

Brunoni, A.R., Suen, P., Bacchi, P.S., Razza, L.B., Klein, I., Santos, Dos, L., A., de Souza Santos, I., Valiengo, da Costa Lane, L., Gallucci-Neto, J., Moreno, M., L., Pinto, B.S., de Cássia Silva Félix, L., de Sousa, J.P., Viana, M.C., Forte, P.M., de Altisent Oliveira Cardoso, M.C., Bittencourt, M.S., Pelosof, R., de Siqueira, L.L., Fatori, D., Benseñor, I., M., 2021. Prevalence and risk factors of psychiatric symptoms and diagnoses before and during the COVID-19 pandemic: findings from the ELSA-Brasil COVID-19 mental health cohort. Psychol. Med. 1-12. https://doi.org/10.1017/ S0033291721001719. Advance online publication. 
Bryant, R.A., 2019. Post-traumatic stress disorder: a state-of-the-art review of evidence and challenges. World Psychiatry 18, 259-269.

Bueno-Notivol, J., Gracia-García, P., Olaya, B., Lasheras, I., López-Antón, R., Santabárbara, J., 2021. Prevalence of depression during the COVID-19 outbreak: A meta-analysis of community-based studies. Int. J. Clin. Health Psychol. 21 (1), 100196. https://doi.org/10.1016/j.ijchp.2020.07.007.

Buhr, K., Dugas, M.J., 2002. The intolerance of uncertainty scale: psychometric properties of the english version. Behav. Res. Ther. 40, 931-945.

Campion, J., Javed, A., Sartorius, N., Marmot, M., 2020. Addressing the public mental health challenge of COVID-19. Lancet Psychiatry 7 (8), 657659. https://doi.org/ 10.1016/S2215-0366(20)30240-6.

Caspi, A., Houts, R.M., Belsky, D.W., Goldman-Mellor, S.J., Harrington, H., Israel, S., Meier, M.H., Ramrakha, S., Shalev, I., Poulton, R., Moffitt, T.E., 2014. The p factor: one general psychopathology factor in the structure of psychiatric disorders? Clin. Psychol. Sci. 2, 119-137.

Celeux, G., Soromenho, G., 1996. An entropy criterion for assessing the number of clusters in a mixture model. J. Classif. 13, 195-212.

Cénat, J.M., Blais-Rochette, C., Kokou-Kpolou, C.K., Noorishad, P.G., Mukunzi, J.N., McIntee, S.E., Dalexis, R.D., Goulet, M.A., Labelle, R.P., 2021. Prevalence of symptoms of depression, anxiety, insomnia, posttraumatic stress disorder, and psychological distress among populations affected by the COVID-19 pandemic: A systematic review and meta-analysis. Psychiatry Res. 295, 113599. https://doi.org/ 10.1016/j.psychres.2020.113599.

Central Statistics Office of Ireland, 2020. In: Cork, I. (Ed.), Census 2016 Reports. Central Statistics Office, Cork, Ireland. Ed.

Cloitre, M., Shevlin, M., Brewin, C.R., Bisson, J.I., Roberts, N.P., Maercker, A., Karatzias, T., Hyland, P., 2018. The international trauma questionnaire: development of a self-report measure of ICD-11 PTSD and complex PTSD. Acta Psychiatr. Scand, 138, 536-546.

Cooke, J.E., Eirich, R., Racine, N., Madigan, S., 2020. Prevalence of posttraumatic and general psychological stress during COVID-19: a rapid review and meta-analysis. Psychiatry Res. 292, 113347, 113347.

Daly, M., Robinson, E., 2021a. Psychological distress and adaptation to the COVID-19 crisis in the United States. J. Psychiatr. Res. 136, 603-609. https://doi.org/10.1016/ j.jpsychires.2020.10.035.

Daly, M., Robinson, E., 2021b. Longitudinal changes in distress in the UK from 2019 to September 2020 during the COVID-19 pandemic. Psychiatry Res. 300, 113920 https://doi.org/10.1016/j.psychres.2021.113920.

Enders, C.K., Bandalos, D.L., 2001. The relative performance of full information maximum likelihood estimation for missing data in structural equation models. Struct. Equ. Model. Multidiscip. J. 8, 430-457.

Fernandez-Rio, J., Cecchini, J.A., Mendez-Gimenez, A., Carriedo, A., 2021. Mental wellbeing profiles and physical activity in times of social isolation by the COVID-19: a latent class analysis. Int. J. Sport Exerc. Psychol. https://doi.org/10.1080/ 1612197X.2021.1877328.

Galatzer-Levy, I.R., Ankri, Y., Freedman, S., Israeli-Shalev, Y., Roitman, P., Gilad, M., Shalev, A.Y., 2013. Early PTSD symptom trajectories: persistence, recovery, and response to treatment: results from the Jerusalem trauma outreach and prevention study (J-TOPS). PLoS One 8, e70084.

Galatzer-Levy, I.R., Bonanno, G.A., 2014. Optimism and death: predicting the course and consequences of depression trajectories in response to heart attack. Psychol. Sci. 25 2177-2188.

Galatzer-Levy, I.R., Huang, S.H., Bonanno, G.A., 2018. Trajectories of resilience and dysfunction following potential trauma: a review and statistical evaluation. Clin. Psychol. Rev. 63, 41-55.

Health Service Executive, 2020. HSE Psychosocial Response to the Covid-19 Pandemic. HSE, Dublin.

Hinz, A., Klein, A.M., Brahler, E., Glaesmer, H., Luck, T., Riedel-Heller, S.G., Wirkner, K., Hilbert, A., 2017. Psychometric evaluation of the generalized anxiety disorder screener GAD-7, based on a large German general population sample. J. Affect. Disord. 210, 338-344.

Hughes, M.E., Waite, L.J., Hawkley, L.C., Cacioppo, J.T., 2004. A short scale for measuring loneliness in large surveys: results from two population-based studies. Res. Aging 26, 655-672.

Jokela, M., Bleidorn, W., Lamb, M.E., Gosling, S.D., Rentfrow, P.J., 2015. Geographically varying associations between personality and life satisfaction in the London metropolitan area. PNAS 112, 725-730.

Kesavayuth, D., Poyago-Theotoky, J., Tran, D.B., Zikos, V., 2020. Locus of control, health and healthcare utilization. Econ. Model. 86, 227-238.

Kim, M., Vermunt, J., Bakk, Z., Jaki, T., Van Horn, M.L., 2016. Modeling predictors of latent classes in regression mixture models. Struct. Equ. Model. Multidiscip. J. 23, 601-614.

Kotov, R., Krueger, R.F., Watson, D., Achenbach, T.M., Althoff, R.R., Bagby, R.M., Brown, T.A., Carpenter, W.T., Caspi, A., Clark, L.A., Eaton, N.R., Forbes, M.K., Forbush, K.T., Goldberg, D., Hasin, D., Hyman, S.E., Ivanova, M.Y., Lynam, D.R. Markon, K., Miller, J.D., Moffitt, T.E., Morey, L.C., Mullins-Sweatt, S.N., Ormel, J., Patrick, C.J., Regier, D.A., Rescorla, L., Ruggero, C.J., Samuel, D.B., Sellbom, M., Simms, L.J., Skodol, A.E., Slade, T., South, S.C., Tackett, J.L., Waldman, I.D., Waszczuk, M.A., Widiger, T.A., Wright, A.G.C., Zimmerman, M., 2017. The hierarchical taxonomy of psychopathology (HiTOP): a dimensional alternative to traditional nosologies. J. Abnorm. Psychol. 126, 454-477.
Kroenke, K., Spitzer, R.L., Williams, J.B., 2001. The PHQ-9: validity of a brief depression severity measure. J. Gen. Intern. Med. 16, 606-613.

Lim, M.H., Holt-Lunstad, J., Badcock, J.C., 2020. Loneliness: contemporary insights into causes, correlates, and consequences. Soc. Psychiatry Psychiatr. Epidemiol. 55, 789-791.

Lo, Y., Mendell, N.R., Rubin, D.B., 2001. Testing the number of components in a normal mixture. Biometrika 88, 767-778.

Malgaroli, M., Galatzer-Levy, I.R., Bonanno, G.A., 2017. Heterogeneity in trajectories of depression in response to divorce is associated with differential risk for mortality. Clin Psychol Sci 5, 843-850.

Manea, L., Gilbody, S., McMillan, D., 2012. Optimal cut-off score for diagnosing depression with the patient health questionnaire (PHQ-9): a meta-analysis. CMAJ Can. Med. Assoc. J. 184, E191-E196 journal de l'Association medicale canadienne.

Masyn, K.E., 2013. Latent Class Analysis and Finite Mixture Modeling. Oxford University Press.

McBride, O., Murphy, J., Shevlin, M., Gibson-Miller, J., Hartman, T.K., Hyland, P., Levita, L., Mason, L., Martinez, A.P., McKay, R., Stocks, T.V., Bennett, K.M., Vallières, F., Karatzias, T., Valiente, C., Vazquez, C., Bentall, R.P., 2020. Monitoring the psychological, social, and economic impact of the COVID-19 pandemic in the population: Context, design and conduct of the longitudinal COVID-19 psychological research consortium (C19PRC) study. Int. J. Methods Psychiatr. Res. 30 (1), e1861. https://doi.org/10.1002/mpr.1861.

McFarland, S., Webb, M., Brown, D., 2012. All humanity is my ingroup: a measure and studies of identification with all humanity. J. Pers. Soc. Psychol. 103, 830-853.

Muthén, B., 2001. Latent Variable Mixture Modeling. Lawrence Erlbaum Associates.

Muthén, B., Muthén, L.K., 2000. Integrating person-centered and variable-centered analyses: growth mixture modeling with latent trajectory classes. Alcohol. Clin. Exp. Res. 24, 882-891.

Muthén, B., Shedden, K., 1999. Finite mixture modeling with mixture outcomes using the EM algorithm. Biometrics 55, 463-469.

Muthén, L.K., Muthén, B.O., 2018. Mplus, 8.2 ed. Muthén \& Muthén, Los Angeles, CA.

Norris, F.H., 1992. Epidemiology of trauma: frequency and impact of different potentially traumatic events on different demographic groups. J. Consult. Clin. Psychol. 60, 409-418.

Nylund, K.L., Asparouhov, T., Muthén, B.O., 2007. Deciding on the number of classes in latent class analysis and growth mixture modeling: a Monte Carlo simulation study. Struct. Equ. Model. Multidiscip. J. 14, 535-569.

Prati, G., Mancini, A.D., 2021. The psychological impact of COVID-19 pandemic lockdowns: a review and meta-analysis of longitudinal studies and natural experiments. Psychol. Med. 51, 201-211.

Reger, M.A., Stanley, I.H., Joiner, T.E., 2020. Suicide Mortality and Coronavirus Disease 2019-A Perfect Storm? JAMA Psychiatry 77 (11), 10931094. https://doi.org/ 10.1001/jamapsychiatry.2020.1060.

Salari, N., Hosseinian-Far, A., Jalali, R., Vaisi-Raygani, A., Rasoulpoor, S., Mohammadi, M., Rasoulpoor, S., Khaledi-Paveh, B., 2020. Prevalence of stress, anxiety, depression among the general population during the COVID-19 pandemic: a systematic review and meta-analysis. Glob. Health 16, 57.

Santabárbara, J., Lasheras, I., Lipnicki, D.M., Bueno-Notivol, J., Pérez-Moreno, M., López-Antón, R., De la Cámara, C., Lobo, A., Gracia-García, P., 2020. Prevalence of anxiety in the COVID-19 pandemic: an updated meta-analysis of community-based studies. Prog. Neuropsychopharmacol. Biol. Psychiatry 109, 110207, 110207.

Sapp, S.G., Harrod, W.J., 1993. Reliability and validity of a brief version of levenson's locus of control scale. Psychol. Rep. 72, 539-550.

Schafer, J.L., Graham, J.W., 2002. Missing data: our view of the state of the art. Psychol. Methods 7, 147-177.

Schwarz, G., 1978. Estimating the dimension of a model. Ann. Stat. 6, 461-464.

Sclove, S.L., 1987. Application of model-selection criteria to some problems in multivariate analysis. Psychometrika 52, 333-343.

Shevlin, M., Butter, S., McBride, O., Murphy, J., Gibson-Miller, J., Hartman, T.K., Levita, L., Mason, L., Martinez, A.P., McKay, R., Stocks, T., Bennett, K., Hyland, P., Bentall, R.P., 2021. Refuting the myth of a 'tsunami' of mental ill-health in populations affected by COVID-19: evidence that response to the pandemic is heterogeneous, not homogeneous. Psychol. Med. 1-9. https://doi.org/10.1017/ S0033291721001665. Advance online publication.

Shevlin, M., Hyland, P., Karatzias, T., 2020. Is posttraumatic stress disorder meaningful in the context of the COVID-19 pandemic? A response to van overmeire's commentary on Karatzias et al. (2020). J. Trauma Stress 33 (5), 866-868. https:// doi.org/10.1002/jts.22592.

Spikol, E., McBride, O., Daly, M., Vallières, F., Butter, S., Bentall, R., \& Hyland, P., 2021. Assessing and protecting the mental health of the nation: a methodological protocol detailing Irish data from the COVID-19 psychological research consortium (C19PRC) study. PsyArXiv. 10.31234/osf.io/v4nrk.

Spitzer, R.L., Kroenke, K., Williams, J.B., Lowe, B., 2006. A brief measure for assessing generalized anxiety disorder: the GAD-7. Arch. Intern. Med. 166, 1092-1097.

Torjesen, I., 2020. Covid-19: mental health services must be boosted to deal with "tsunami" of cases after lockdown. BMJ 369, m1994.

Van Overmeire, R., 2020. The methodological problem of identifying criterion a traumatic events during the COVID-19 era: a commentary on Karatzias et al, 2020 J. Trauma Stress 33 (5), 864-865. https://doi.org/10.1002/jts.22594.

Wu, T., Jia, X., Shi, H., Niu, J., Yin, X., Xie, J., Wang, X., 2021. Prevalence of mental health problems during the COVID-19 pandemic: a systematic review and metaanalysis. J. Affect. Disord. 281, 91-98. 